\title{
Near- infrared, mode-locked waveguide lasers with multi-GHz repetition rates
}

\begin{abstract}
A. Choudhary, A. A. Lagatsky, Z. Y. Zhang, K. J. Zhou, Q. Wang, et al.
\end{abstract}

A. Choudhary, A. A. Lagatsky, Z. Y. Zhang, K. J. Zhou, Q. Wang, R. A. Hogg, K. Pradeesh, E. U. Rafailov, B. Resan, A. E. H. Oehler, K. J. Weingarten, W. Sibbett, C. T. A. Brown, D. P. Shepherd, "Near- infrared, mode-locked waveguide lasers with multi-GHz repetition rates," Proc. SPIE 8959, Solid State Lasers XXIII: Technology and Devices, 895913 (28 February 2014); doi: $10.1117 / 12.2035639$ 


\title{
Near-infrared, mode-locked waveguide lasers with multi-GHz repetition rates
}

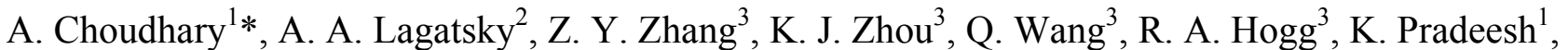 \\ E. U. Rafailov ${ }^{4}$, B. Resan ${ }^{5}$, A. E. H. Oehler ${ }^{5}$, K. J. Weingarten ${ }^{5}$, W. Sibbett ${ }^{2}$, C. T. A. Brown ${ }^{2}$ and D. \\ P. Shepherd ${ }^{1}$ \\ ${ }^{1}$ Optoelectronics Research Centre, University of Southampton, Southampton, SO171BJ, United Kingdom \\ ${ }^{2}$ SUPA, School of Physics and Astronomy, University of St Andrews, North Haugh, St Andrews, KY169SS, \\ United Kingdom \\ ${ }^{3}$ EPSRC National Centre for III-V technologies, Department of Electronic and Electrical Engineering, \\ University of Sheffield, Sheffield, S13JD, United Kingdom \\ ${ }^{4}$ Photonics and Nanoscience Group, School of Engineering, Physics and Mathematics, University of Dundee, \\ Dundee, DD14HN, United Kingdom \\ ${ }^{5}$ Time-Bandwidth Products AG, Ruetistrasse 12, CH-8952 Schlieren, Switzerland \\ *ac12g10@orc.soton.ac.uk
}

\begin{abstract}
In this work, we discuss mode-locking results obtained with low-loss, ion-exchanged waveguide lasers. With $\mathrm{Yb}^{3+}$-doped phosphate glass waveguide lasers, a repetition rate of up to $15.2 \mathrm{GHz}$ was achieved at a wavelength of $1047 \mathrm{~nm}$ with an average power of $27 \mathrm{~mW}$ and pulse duration of $811 \mathrm{fs}$. The gap between the waveguide and the SESAM introduced negative group velocity dispersion via the Gires Tournois Interferometer (GTI) effect which allowed the soliton mode-locking of the device. A novel quantum dot SESAM was used to mode-lock $\mathrm{Er}^{3+}, \mathrm{Yb}^{3+}$-doped phosphate glass waveguide lasers around $1500 \mathrm{~nm}$. Picosecond pulses were achieved at a maximum repetition rate of $6.8 \mathrm{GHz}$ and an average output power of 30 $\mathrm{mW}$. The repetition rate was tuned by more than $1 \mathrm{MHz}$ by varying the pump power.
\end{abstract}

Keywords: Ytterbium doped gain media, Erbium/Ytterbium doped gain media, waveguide laser, channel waveguides, mode-locked laser, quantum dot devices.

\section{INTRODUCTION}

High-repetition-rate lasers (i.e. $>1 \mathrm{GHz}$ ) lasers have gained considerable interest over the last decade owing to various applications in optical frequency metrology [1], calibration of astronomical spectrographs [2], optical sampling [3] and non-linear microscopy [4]. Diode-pumped, solid-state waveguide lasers with integrated saturable absorber elements can be used as high repetition-rate laser sources. These compact devices offer several advantages such as a low lasing threshold, high slope efficiency and a low mode-locking threshold due to the strong saturation of the gain medium and the saturable absorber owing to the small mode sizes. These devices can operate over various spectral regimes and can be mass-produced using standard micro-photonic fabrication techniques.

Using the standard cleanroom processes it is also possible to integrate dispersion compensating elements, Bragg-mirrors structures and possibly saturable absorbers on a single chip. To this end, a sub-picosecond Erbium-doped aluminasilicate glass waveguide laser with a repetition-rate of $400 \mathrm{MHz}$ and wavelength around $1.5 \mu \mathrm{m}$ was realised by Byun et al. [5]. However, the output power was limited to $\sim 1.2 \mathrm{~mW}$. There have been several previous reports of ultrafast lasers with waveguides as a gain media and the saturable absorber in an external cavity configuration with repetition rates of

Solid State Lasers XXIII: Technology and Devices, edited by W. Andrew Clarkson, Ramesh K. Shori, Proc. of SPIE Vol. 8959, 895913 - (C) 2014 SPIE · CCC code: 0277-786X/14/\$18 · doi: 10.1117/12.2035639 
below $1 \mathrm{GHz}$ [6-9], and recently picosecond operation of a femtosecond-written glass waveguide laser at a repetition rate of $1.5 \mathrm{GHz}[10]$ has been demonstrated using graphene as the saturable absorber element.

In this paper we present our high-repetition rate, ion-exchanged waveguide lasers fabricated in phosphate glasses. The $\mathrm{Yb}^{3+}$-doped IOG-1 waveguides were polished to lengths of $20 \mathrm{~mm}, 9.4 \mathrm{~mm}, 8 \mathrm{~mm}$ and $6.5 \mathrm{~mm}$ resulting in repetition rates of $4.9 \mathrm{GHz}, 10.2 \mathrm{GHz}, 12 \mathrm{GHz}$ and $15 \mathrm{GHz}$, respectively [11, 12]. Pulse durations of $\sim 800 \mathrm{fs}$ with average power of few tens of $\mathrm{mWs}$ were achieved around $1050 \mathrm{~nm}$ from these devices. Negative group velocity dispersion was introduced into the cavity by controlling the gap between the SESAM and the waveguide via the Gires Tournois Interferometer (GTI) effect. Er,Yb-doped IOG-1 glass waveguides were also fabricated by ion-exchange and two samples of lengths $20 \mathrm{~mm}$ and $14.5 \mathrm{~mm}$ generated picosecond pulses at a repetition rate of $4.8 \mathrm{GHz}$ and $6.8 \mathrm{GHz}$ [13] at $1500 \mathrm{~nm}$. A novel quantum-dot (QD) SESAM [14] was utilised to initiate self-starting mode-locking. The repetition rate of the waveguide laser was also tuned by controlling the pump power, which could be a promising technique for frequency comb stabilisation.

\section{EXPERIMENTAL DETAILS}

\subsection{Waveguide fabrication}

A 200-nm-thick layer of aluminium (Al) was deposited by e-beam evaporation on the polished $\mathrm{Yb}^{3+}$-doped and $\mathrm{Er}^{3+}, \mathrm{Yb}^{3+}$-doped phosphate glass samples (IOG-1 from Schott Glass technologies Inc), following which a 1.3- $\mu \mathrm{m}$-thick photoresist layer (S1813) was spin-coated on them. Using photolithography, channel openings of widths $1 \mu \mathrm{m}$ to $10 \mu \mathrm{m}$ in steps of $0.2 \mu \mathrm{m}$ were opened and the resist-masked samples were chemically etched to transfer the photoresist mask onto the metal layer. After solvent removal of the photoresist, the samples were immersed in a molten salt mixture comprising of $45 \mathrm{~mol} \% \mathrm{KNO}_{3}-50 \mathrm{~mol} \% \mathrm{NaNO}_{3}-5 \mathrm{~mol} \% \mathrm{AgNO}_{3}$ in an ion-exchange furnace. The glass samples were kept at a temperature of $325^{\circ} \mathrm{C}$ for 10 minutes for the $\mathrm{Yb}^{3+}$-doped glass and for 30 minutes for the $\mathrm{Er}^{3+}, \mathrm{Yb}^{3+}$-doped glass. The $\mathrm{Na}^{+}$ions in the glass were exchanged with the $\mathrm{K}^{+}$and the $\mathrm{Ag}^{+}$ions in the ion-exchange melt, leading to a local increase in the refractive index. Next, the metal mask was chemically removed and the $\mathrm{Yb}^{3+}$-doped glass samples were polished to lengths of $20 \mathrm{~mm}, 9.4 \mathrm{~mm}, 8 \mathrm{~mm}$ and $6.5 \mathrm{~mm}$ and the $\mathrm{Er}^{3+}, \mathrm{Yb}^{3+}$-doped glass samples were polished to lengths of $20 \mathrm{~mm}$ and $14.5 \mathrm{~mm}$.

\subsection{Quantum dot SESAM fabrication}

The QD-SESAM [14] used for mode-locking the $\mathrm{Er}^{3+}, \mathrm{Yb}^{3+}$-doped glass around $1.5 \mu \mathrm{m}$ was grown in a solid-source molecular beam epitaxy machine. 31 pairs of GaAs $(115 \mathrm{~nm})$ and $\mathrm{Al}_{0.98} \mathrm{Ga}_{0.02} \mathrm{As}(134 \mathrm{~nm})$ were grown on a $\mathrm{GaAs}$ substrate to form the distributed Bragg reflector (DBR) structure. On top of the DBR mirror, a dot in well (DWELL) structure was grown. The DWELL structure comprised of a 1-nm-thick layer of $\operatorname{In}_{0.18} \mathrm{Ga}_{0.82} \mathrm{As}$ followed by the InGaAs/GaAs quantum dot layer and finally a 6-nm-thick layer of $\mathrm{In}_{0.31} \mathrm{Ga}_{0.69} \mathrm{As}$. On top of the DWELL structure, a GaAs capping layer was grown. The In-layers were grown at a temperature of $530^{\circ} \mathrm{C}$ and the GaAs layers were grown at $565^{\circ} \mathrm{C}$.

\subsection{Experimental setup}

The waveguides were pumped by a single-mode, fibre-coupled laser diode delivering a power of up to $850 \mathrm{~mW}$ at a wavelength of $974 \mathrm{~nm}$ (3S photonics). The output from the pump was collimated by an aspheric lens with a focal length of $8 \mathrm{~mm}$ and was coupled into the waveguide through an output coupling mirror $(\mathrm{R}=98 \%$ at the lasing wavelength and $\mathrm{R}<0.1 \%$ at the pump wavelength) by either an aspheric lens with focal length of $11 \mathrm{~mm}$ for pumping the $\mathrm{Yb}^{3+}$-doped glass waveguides or an aspheric lens with focal length of $15.4 \mathrm{~mm}$ for pumping the $\mathrm{Er}^{3+}, \mathrm{Yb}^{3+}$-doped glass waveguides. After the $\mathrm{f}=8 \mathrm{~mm}$ collimating lens, a combination of a half-wave plate and an optical isolator was installed in the pump path to protect the laser diode from feedback from the waveguide. The waveguide cavity was completed by end-butting a high reflectivity (HR) mirror for continuous wave (CW) characterisation or a SESAM for mode-locking experiments. A commercially available SESAM from Batop $\mathrm{GmbH}$ was used for mode-locking the $\mathrm{Yb}^{3+}$-doped glass waveguides and the QD-SESAM was used for mode-locking the $\mathrm{Er}^{3+}, \mathrm{Yb}^{3+}$-doped glass waveguides. A dichroic mirror installed before the launching lens was used to separate the pump and the laser beams. The laser beam reflected from the dichroic mirror was then passed through a combination of a half-wave plate and an isolator and then coupled into a single-mode fibre. 
The output of this fibre was split by a 3-dB coupler and was fed into a spectrometer and a radio frequency (RF) spectrum analyser. A flip mirror was placed before the coupling stage, which was used to steer the beam to an autocorrelator to measure the pulse duration. The output power was measured before the isolator using a thermal power meter.

\section{MODE-LOCKED YB:PHOSPHATE GLASS WAVEGUIDE LASER}

With the 20-mm-long Yb:phosphate glass waveguide sample, mode-locked operation was observed at an average output power of $19 \mathrm{~mW}$. On increasing the pump power, an output power of up to $32 \mathrm{~mW}$ was achieved at a repetition rate of 4.9 GHz as seen from Figure 1(a). The pulses were measured to be $740 \mathrm{fs}$ and had a good fit to a $\mathrm{sech}^{2}$ profile as shown in Figure 1 (b). The mode-locked laser spectrum was found to be centred at $1058.3 \mathrm{~nm}$ and had a full-width-halfmaximum (FWHM) of $2.3 \mathrm{~nm}$ (Figure 1(c)), resulting in a time-bandwidth product of 0.46 .
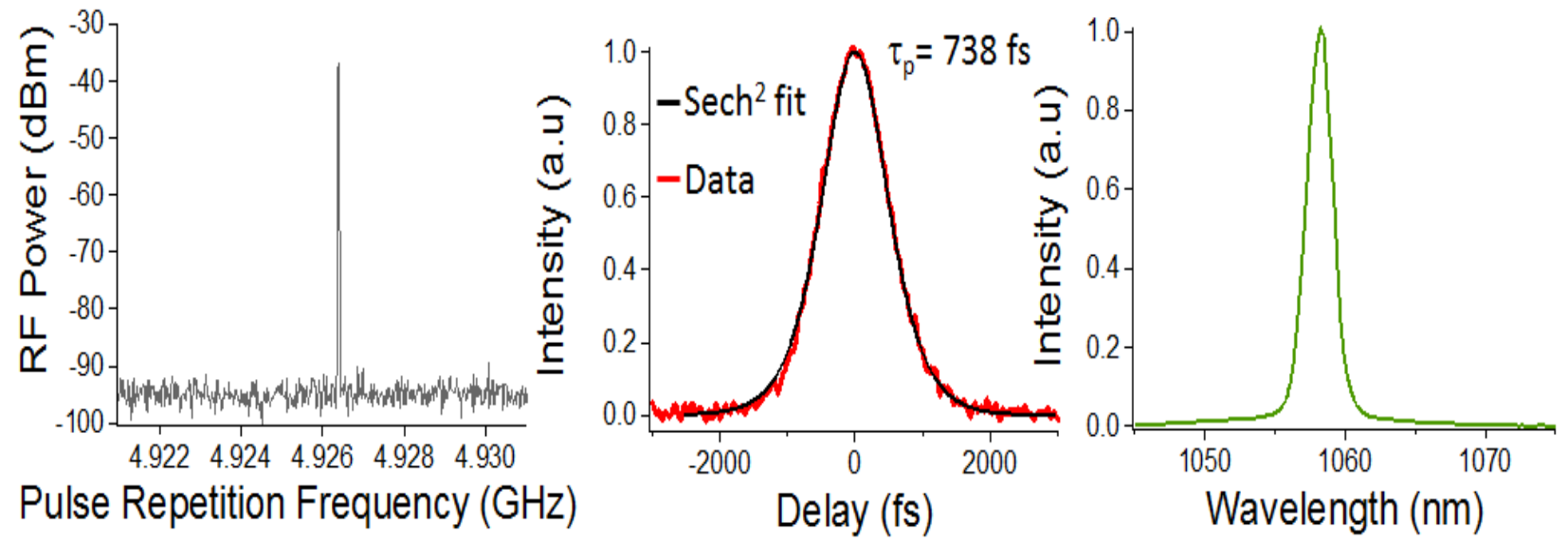

Figure 1. (a). RF spectrum, (b) autocorrelation trace, and (c) optical spectrum measured for the 20-mm-long $\mathrm{Yb}^{3+}$-doped phosphate glass waveguide laser.

Similarly, mode-locking experiments were carried out with the 9.4-mm-long, 8-mm-long and 6.5-mm-long waveguide sample and the results obtained have been summarized in Table 1. A maximum repetition rate of $15.2 \mathrm{GHz}$ was obtained with the 6.5-mm-long waveguide sample.

Table 1: Summary of results obtained with different $\mathrm{Yb}^{3+}$-doped glass waveguide lasers.

\begin{tabular}{|c|c|c|c|c|c|}
\hline $\begin{array}{c}\text { Sample length } \\
(\mathbf{m m})\end{array}$ & $\begin{array}{c}\text { Repetition- } \\
\text { rate (GHz) }\end{array}$ & $\begin{array}{c}\text { Pulse } \\
\text { Duration } \\
(\mathbf{f s})\end{array}$ & $\begin{array}{c}\text { Center } \\
\text { wavelength } \\
\mathbf{( n m})\end{array}$ & $\begin{array}{c}\text { Time- } \\
\text { bandwidth } \\
\text { product }\end{array}$ & $\begin{array}{c}\text { Output } \\
\text { power } \\
(\mathbf{m W})\end{array}$ \\
\hline 20 & 4.9 & 738 & 1058.3 & 0.46 & 32 \\
\hline 9.4 & 10.4 & 757 & 1041.4 & 0.56 & 60 \\
\hline 8 & 12 & 824 & 1045.7 & 0.43 & 45 \\
\hline 6.5 & 15.2 & 811 & 1047.4 & 0.49 & 27 \\
\hline
\end{tabular}

The experimentally measured critical pulse energy for the 20-mm-long waveguide laser was $0.2 \mathrm{~nJ}$, which is an order of magnitude lower than the theoretically estimated value for the non-soliton mode-locking case (see equation 16 of [15]). The low-threshold mode-locking from our waveguide lasers can be attributed to a soliton formation mechanism. The critical pulse energy was calculated to be $0.095 \mathrm{~nJ}$ for the soliton mode-locking case (see equation 27 of [15]) which is in good agreement with our experimentally observed values. The necessary group velocity dispersion (GVD) is introduced 
into the cavity by controlling the gap between the SESAM and the waveguide, which essentially behaves as a GiresTournois interferometer (GTI) structure. The net dispersion in the cavity was estimated to be around $-6200 \mathrm{fs}^{2}[16]$ for the 20-mm-long-waveguide cavity, where $920 \mathrm{fs}^{2}$ is the contribution from the $\mathrm{Yb}^{3+}$-glass waveguide and $-7120 \mathrm{fs}^{2}$ is the contribution from the GTI.

\section{MODE-LOCKED ER,YB:PHOSPHATE GLASS WAVEGUIDE LASER}

With the 20-mm-long Er,Yb:phosphate glass waveguide sample, Q-switched modelocking was observed at an incident pump power of $415 \mathrm{~mW}$ which resulted in an output power of $5.6 \mathrm{~mW}$. The repetition rate was measured to be $370 \mathrm{kHz}$ and the Q-switched pulse envelope duration was measured to be $106 \mathrm{~ns}$. On increasing the pump power to $513 \mathrm{~mW}$, selfstarting CW mode-locking was observed with a corresponding output power of $6.7 \mathrm{~mW}$. The total dispersion in the cavity was estimated to be about $-2000 \mathrm{fs}^{2}$, with the contribution of the Er,Yb:phosphate glass and the GTI being -840 $\mathrm{fs}^{2}$ and the $-1160 \mathrm{fs}^{2}$, respectively. The RF spectrum was centred around $4.8 \mathrm{GHz}$ as shown in figure 2 (a). On increasing the pump power further, a maximum output power of $9 \mathrm{~mW}$ was measured The pulses were measured to be 2.5 ps and had a good fit to a sech ${ }^{2}$ profile as shown in Figure 2 (b). The mode-locked laser spectrum was found to be centred at $1556 \mathrm{~nm}$ and had a full-width-half-maximum (FWHM) of $1.2 \mathrm{~nm}$ (Figure 2(c)), resulting in a time-bandwidth product of 0.36 .
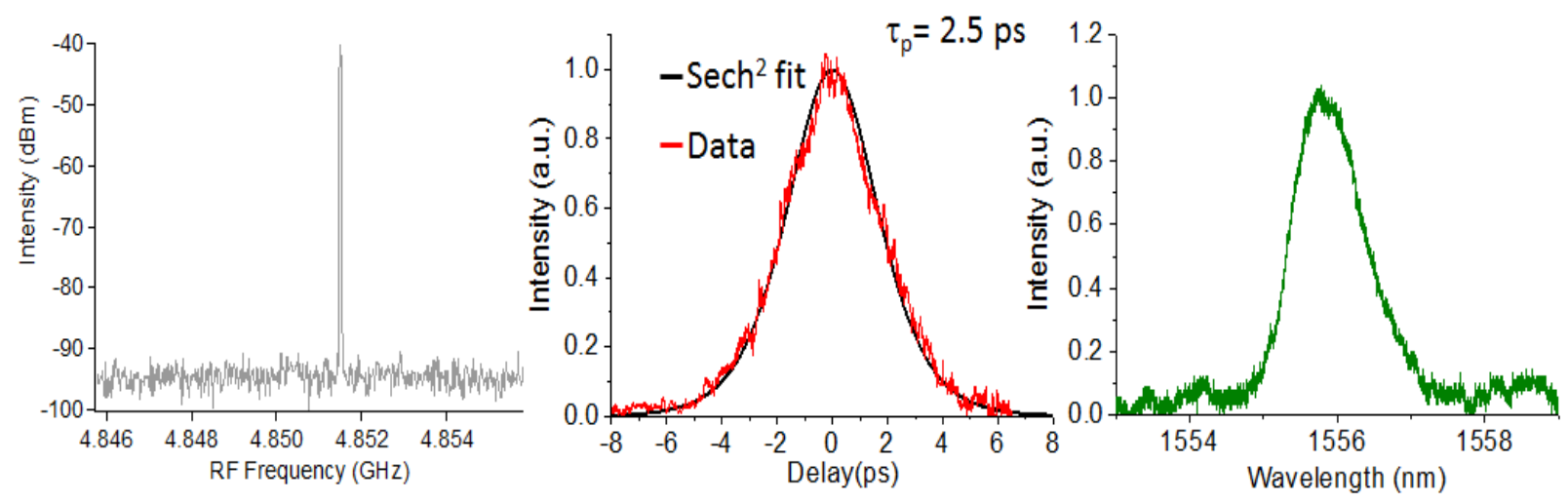

Figure 2. (a). RF spectrum, (b) autocorrelation trace, and (c) optical spectrum measured for the 20-mm-long $\mathrm{Er}^{3+}, \mathrm{Yb}^{3+}-$ doped phosphate glass waveguide laser.

A similar experiment was carried out with the 14.5 -mm-long sample and a repetition rate of $6.8 \mathrm{GHz}$ and a maximum output power of $30 \mathrm{~mW}$ was achieved. The results for both the waveguide samples has been summarised in Table 2 .

Table 2: Summary of results obtained with different $\mathrm{Er}^{3+}, \mathrm{Yb}^{3+}$-doped glass waveguide lasers.

\begin{tabular}{|c|c|c|c|c|c|}
\hline $\begin{array}{c}\text { Sample length } \\
(\mathbf{m m})\end{array}$ & $\begin{array}{c}\text { Repetition- } \\
\text { rate (GHz) }\end{array}$ & $\begin{array}{c}\text { Pulse } \\
\text { Duration } \\
(\mathbf{p s})\end{array}$ & $\begin{array}{c}\text { Center } \\
\text { wavelength } \\
(\mathbf{n m})\end{array}$ & $\begin{array}{c}\text { Time- } \\
\text { bandwidth } \\
\text { product }\end{array}$ & $\begin{array}{c}\text { Output } \\
\text { power } \\
(\mathbf{m W})\end{array}$ \\
\hline 20 & 4.8 & 2.5 & 1556 & 0.36 & 9 \\
\hline 14.5 & 6.8 & 5.4 & 1544.4 & 0.52 & 30 \\
\hline
\end{tabular}

After mode-locking was achieved at a repetition rate of $6.8033 \mathrm{GHz}$, pump power was increased further to study its effect on the repetition-rate. It was found that the repetition-rate decreased by more than $1 \mathrm{MHz}$ on increasing the pump 
power by $100 \mathrm{~mW}$ as seen from figure 3. This is attributed to the thermal expansion of the waveguide due to the increasing pump power.

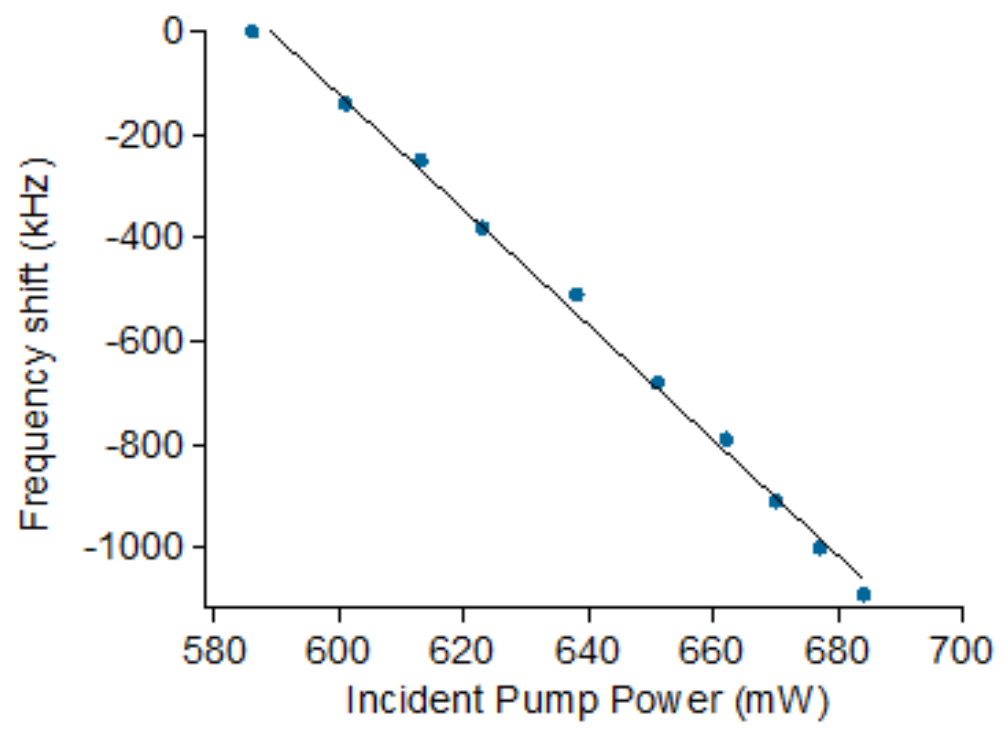

Figure 3. The change in the repetition-rate of the 14.5-mm-long waveguide laser on increasing the pump power.

\section{CONCLUSIONS}

In conclusion, diode-pumped, solid-state waveguide lasers were demonstrated around two different spectral regimes. Using $\mathrm{Yb}^{3+}$-doped phosphate glasses, sub-picosecond operation was demonstrated around $1 \mu \mathrm{m}$ with a repetition-rate of up to $15 \mathrm{GHz}$. Dispersion control in the laser cavity was facilitated by controlling the separation between the waveguide and the SESAM promoting self-starting, soliton mode-locked operation. Using $\mathrm{Er}^{3+}, \mathrm{Yb}^{3+}$-doped phosphate glasses, we have also demonstrated the first waveguide laser mode-locked by a quantum dot SESAM. Around $1.5 \mu \mathrm{m}$, a repetition rate of up to $6.8 \mathrm{GHz}$ was achieved. The central repetition-rate was accurately controlled by varying the incident pump power which can offer a route for on-chip frequency comb stabilisation. Future work would also include, mode-locking of ion-exchanged Tm-doped waveguides [17] to demonstrate a high repetition-rate source around $2 \mu \mathrm{m}$.

\section{ACKNOWLEDGEMENTS}

This project is funded by the UK Engineering and Physical Sciences Research Council (EPSRC) through grants EP/H035745/1, EP/H038035/1 and EP/J008052/1 and by EU FP7 project FastDot. We would also like to acknowledge Prof. J.Wilkinson for providing the Er,Yb-doped IOG-1 glass. We would also like to thank Neil Sessions and Dr. Senthil Ganapathy for useful discussions.

\section{REFERENCES}

[1] Jones, D. J., Diddams, S. A., Ranka, J. K., Stentz, A., Windeler, R. S., Hall, J. L., and S. T. Cundiff, "Carrierenvelope phase control of femtosecond mode-locked lasers and direct optical frequency synthesis," Science 288 (5466), 635-639 (2000).

[2] Chih-Hao, Li, Benedick, A. J., Fendel, P., Glenday, A. G., Kartner, F. X., Phillips, D. F., Sasselov, D., Szentgyorgyi, A., and Walsworth, R. L., "A laser frequency comb that enables radial velocity measurements with a precision of $1 \mathrm{~cm} \mathrm{~s}-1, "$ Nature 452 (7187), 610-612 (2008). 
[3] Bartels, A., Cerna, R., Kistner, C., Thoma, A., Hudert, F., Janke, C., and Dekorsy, T., "Ultrafast time-domain spectroscopy based on high-speed asynchronous optical sampling," Rev. Sci. Instrum. 78 (3), 035107 (2007).

[4] Chu, S.-W., Liu, T.-M., Sun, C.-K., Lin, C.-Y., and Tsai, H.-J., "Real-time second-harmonic-generation microscopy based on a 2-GHz repetition rate Ti:sapphire laser," Opt. Express 11 (8), 933-938 (2003).

[5] Byun, H., Hanjani, A., Frolov, S., Ippen, E. P., Pudo, D., Shmulovich, J., and Kartner, F. X., "Integrated lowjitter 400-MHz femtosecond waveguide laser," IEEE Photon. Tech. Lett. 21 (12), 763-765 (2009).

[6] Valle, G.D, Osellame, R., Galzerano, G., Chiodo, N., Cerullo, G., Laporta, P., Svelto, O., Morgner, U., Rozhin, A. G., Scardaci, V., and Ferrari, A. C., "Passive mode locking by carbon nanotubes in a femtosecond laser written waveguide laser," Appl. Phys. Lett. 89 (23), 231115 (2006).

[7] Beecher, S. J., Thomson, R. R., Psaila, N. D., Sun, Z., Hasan, T., Rozhin. A. G., Ferrari, A. C., and Kar, A. K., "320 fs pulse generation from an ultrafast laser inscribed waveguide laser mode-locked by a nanotube saturable absorber," Appl. Phys. Lett. 97 (11), 111114 (2010).

[8] Schlager, J. B., Callicoatt, B. E., Mirin, R. P., and Sanford, N. A., "Passively mode-locked waveguide laser with low residual jitter," IEEE Photon. Technol. Lett. 14 (9), 1351-1353 (2002).

[9] Schlager, J. B., Callicoatt, B. E., Mirin, R. P., Sanford, N. A., Jones, D. J., and Ye, J., "Passively mode-locked glass waveguide laser with 14-fs timing jitter," Opt. Lett. 28 (23), 2411-2413 (2003).

[10] Mary, R., Brown, G., Beecher, S. J., Torrisi, F., Milana, S., Popa, D., Hasan, T., Sun, Z., Lidorikis, E., Ohara, S., Ferrari, A. C., and Kar, A.K., "1.5 GHz picosecond pulse generation from a monolithic waveguide laser with a graphene-film saturable output coupler,” Opt. Express 21 (7), 7943-7950 (2013).

[11] Choudhary, A., Lagatsky, A. A., Kannan, P., Sibbett, W., Brown, C. T. A., and Shepherd, D. P., "Diodepumped femtosecond solid-state waveguide laser with a $4.9 \mathrm{GHz}$ pulse repetition rate," Opt. Lett. 37 (21), 4416-4418 (2012).

[12] Lagatsky, A. A., Choudhary, A., Kannan, P., Shepherd, D. P., Sibbett, W., and Brown, C. T. A., "Fundamentally mode-locked, femtosecond waveguide oscillators with multi-gigahertz repetition frequencies up to $15 \mathrm{GHz}$," Opt. Express. 21 (17), 19608-19614 (2013).

[13] Choudhary, A., Lagatsky, A. A., Zhang, Z. Y., Zhou, K. J., Wang, Q., Hogg, R. A., Pradeesh, K., Rafailov, ,E. U., Sibbett, W., Brown, C. T. A., and Shepherd, D. P., "A diode-pumped $1.5 \mu \mathrm{m}$ waveguide laser mode-locked at $6.8 \mathrm{GHz}$ by a quantum dot SESAM," Laser Phys. Lett 10 (10), 105803 (2013).

[14]Zhang, Z. Y., Oehler, A. E. H., Resan, B., Kurmulis, S., Zhou, K. J., Wang, Q., Mangold, M., Suedmeyer, T., Keller, U., Weingarten, K. J., and Hogg, R. A., "1.55 $\mu \mathrm{m}$ InAs/GaAs Quantum Dots and High Repetition Rate Quantum Dot SESAM Mode-locked Laser," Sci. Rep. 2, 477 (2012).

[15] Honninger, C., Paschotta, R., Morier-Genoud, F., Moser, M., and Keller, U., "Q-switching stability limits of continuous-wave passive mode locking," J. Opt. Soc. Am. B 16 (1), 46-56 (1999).

[16] Kärtner, F.X. and Keller, U., "Stabilization of soliton like pulses with a slow saturable absorber," Opt. Lett. 20 (1), 16-18 (1995).

[17] Choudhary, A., Kannan, P., Mackenzie, J. I., Feng, X., and Shepherd, D.P., “Ion-exchanged $\mathrm{Tm}^{3+:}$ glass channel waveguide laser," Opt. Lett 38 (7), 1146-1148 (2013). 